\title{
Capsule Commentary on Lewis et al., Innovation in the Safety Net: Integrating Community Health Centers Through Accountable Care
}

\author{
Donovan T. Maust, MD, MS \\ Department of Psychiatry, University of Michigan, Ann Arbor, MI, USA.
}

$\mathrm{L}$ ewis et al. ${ }^{1}$ explore to what extent community health centers (CHCs) are being incorporated into accountable care organizations (ACOs). CHCs play a large role in caring for underserved communities and vulnerable populations, yet they are often segmented from other health care providers. The authors suggest ACOs could provide a mechanism through which CHCs integrate with other providers.

This work is notable simply for that fact that it is actual data provided by real ACOs. Since passage of the Affordable Care Act, thought pieces have extolled the virtues of ACOs for their potential to reorganize payment and care delivery to achieve the triple aim of better care and better health at a lower cost. ${ }^{2}$ Publications have examined market features associated with ACO formation ${ }^{3}$ and care in ACO-like healthcare systems, ${ }^{4}$ but there have been few analyses published using either data provided by an ACO or about actual ACO patient populations.

Therefore, the work of Lewis et al. is a rare example of information collected from actual ACOs. They start with the National Survey of ACOs, which includes all ACOs in the United States as of August 2012, including both federal and commercial payers. Of 292 potentially eligible organizations, $173(70 \%)$ provided information about organizational characteristics; 18 participated in semi-structured telephone interviews. The authors find that $28 \%$ of ACOs include a $\mathrm{CHC}$ and are largely similar to non-CHC ACOs in terms of organization, size, and capabilities. In addition, $\mathrm{ACO}+\mathrm{CHCs}$ had more experience with patient-centered medical homes, public reporting and risk bearing. Ultimately, the qualitative inter- views suggest that $\mathrm{CHCs}$ were seen as helping their respective ACOs through their expertise in primary care transformation and caring for high-need patients, both areas likely critical for ACO success.

The authors note that it is not possible to determine causality and know whether these relationships would have developed outside of ACO-specific initiatives. Regardless, the ACO experiment is an important one occurring in health policy right now. Understanding baseline characteristics is an important first step, but ongoing analyses that can help both define and then understand success and failure will be critical.

Conflict of Interest: The author has no conflicts of interest with any of the material in this manuscript.

Corresponding Author: Donovan T. Maust, MD, MS; Department of Psychiatry University of Michigan, Ann Arbor, MI 48109, USA (e-mail: maustd@umich.edu).

\section{REFERENCES}

1. Lewis VA, Colla CH, Schoenherr KE, Shortell SM, Fisher ES. Innovation in the Safety Net: Integrating Community Health Centers through Accountable Care. JGIM. doi:10.1007/s11606-014-2911-0.

2. Berwick DM. Making good on ACOs' promise-the final rule for the Medicare shared savings program. NEJM. 2011;365(19):1753-6.

3. Lewis VA, Colla CH, Carluzzo KL, Kler SE, Fisher ES. Accountable Care Organizations in the United States: Market and Demographic Factors Associated with Formation. Health services research. 2013;48(6):1840-58.

4. Anderson RE, Ayanian JZ, Zaslavsky AM, McWilliams JM. Quality of Care and Racial Disparities in Medicare Among Potential ACOs. JGIM. Epub ahead of print. doi:10.1007/s11606-014-2900-3.

Published online August 5, 2014 